\title{
CYP17 Inhibitor CFG920
}

National Cancer Institute

\section{Source}

National Cancer Institute. CYP17 Inhibitor CFG920. NCI Thesaurus. Code C102855.

An orally available inhibitor of the steroid 17-alpha-hydroxylase/C17,20 lyase (CYP17A1 or CYP17), with potential antiandrogen and antineoplastic activities. Upon oral administration, CYP17 inhibitor CFG920 inhibits the enzymatic activity of CYP17A1 in both the testes and adrenal glands, thereby inhibiting androgen production. This may decrease androgen-dependent growth signaling and may inhibit cell proliferation of androgen-dependent tumor cells. The cytochrome P450 enzyme CYP17A1, localized to the endoplasmic reticulum, exhibits both 17alpha-hydroxylase and 17,20-lyase activities, and plays a key role in the steroidogenic pathway that produces steroidal hormones. 